\title{
Technology for reducing the consumption and losses of electrical energy in the power supply systems of railway consumers
}

\author{
Vasily Cheremisin ${ }^{1}$, Yury Demin ${ }^{2}$, Alexander Komyakov ${ }^{1,{ }^{*}}$ and Vladimir Ivanchenko ${ }^{1}$ \\ ${ }^{1}$ Omsk State Transport University, 644046, Marx av., 35, Omsk, Russia \\ ${ }^{2}$ Siberian State University of Water Transport, 630099, Schetinkina st., Novosibirsk, Russia
}

\begin{abstract}
The paper is devoted to the development of technology for reducing the consumption and losses of electrical energy of railway transport enterprises on the basis of the concept of "smart enterprise". A design solution to the monitoring and management system for energy efficiency indicators was proposed; monitored parameters and influencing factors were determined. The application of the simulation model in the MATLAB/Simulink program for determining the set values of the monitored system parameters, namely, power losses and power factor depending on the influencing factors, is considered. The approximating equation is obtained. Specific power losses were calculated for various control options.
\end{abstract}

\section{Introduction}

Nowadays, JSC "RZD" pays serious attention to increasing the efficiency of operation of non-traction railway consumers. To monitor the energy efficiency indicators, the automated information system for energy saving and energy efficiency enhancement of JSC "RZD" (AIS "Energy Efficiency") was developed, whose task is to monitor the implementation of measures to improve energy efficiency quarterly.

Unfortunately, measures taken to improve the operational efficiency of non-traction railway consumers are currently insufficient, since they do not provide for monitoring the power consumption of the structural unit, identifying sections with wasteful consumption of fuel and energy resources, and determining the level of effective consumption and losses of electrical energy.

One of the effective ways to identify the wasteful use of electrical energy is to analyze the specific consumption per unit of output (work). In this case, an indicator related to the main production activity of an enterprise and having a high correlation coefficient with electric power consumption is taken as the work meter [1].

For example, Fig. 1 shows the values of the specific annual electric power consumption per reduced unit of repair for two departments: the service locomotive depot (SLD) Moskovka and the locomotive maintenance station (PTOL) Irtyshskoe.

\footnotetext{
*Corresponding author: tskom@mail.ru
} 


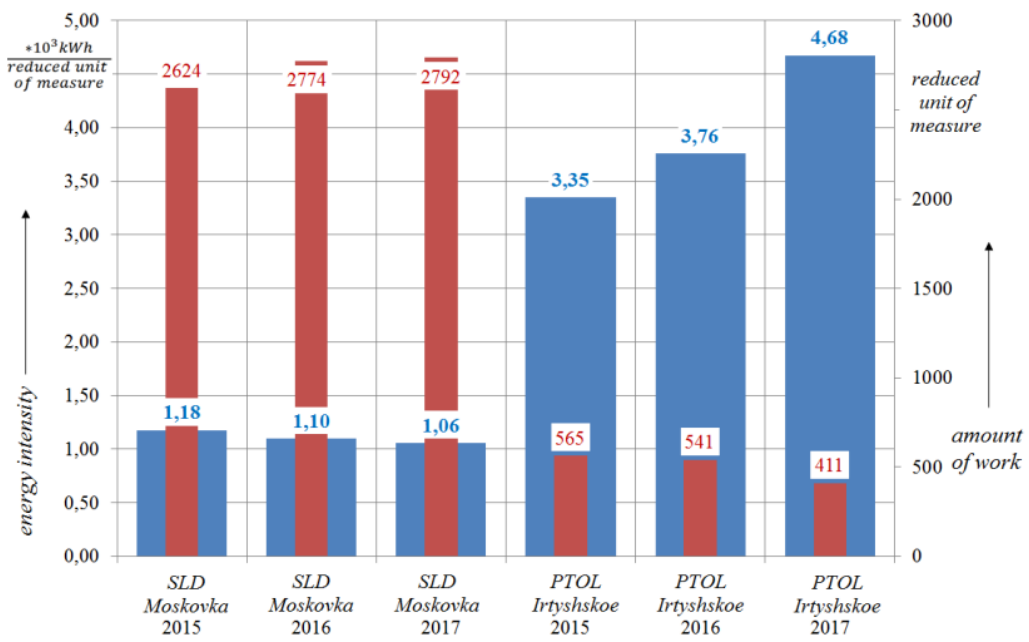

Fig. 1. Annual specific electric energy consumption and the volume of repair works of locomotives for SLD Moskovka and PTOL Irtyshskoe on the results of 2015, 2016, and 2017.

The specific consumption in SLD Moskovka is relatively stable, while PTOL Irtyshskoe shows a significant annual growth of this indicator (in three years - by 1.4 times). Therefore, in this case, it is advisable to pay attention to PTOL Irtyshskoe from the point of view of the search for the causes of irrational electric energy consumption. However, to effectively solve this problem, it is necessary to perform decomposition of the selected enterprise to the level of shops, departments, production sites and perform at this level an analysis of energy efficiency indicators. In this case, a number of problems arise:

a) low equipping of shops with technical means for accounting of electrical energy;

b) lack of strict accounting for work performed at the shop level;

c) inadequate equipping of power supply systems of enterprises with equipment that allows controlling the process of electric energy consumption.

From this point of view, one of the most promising ways of development is the implementation of the concept of "smart enterprise". In Russia and abroad, there are known "smart home" and "smart station" projects, which are primarily aimed at reducing electric energy consumption by the semi-constant component of electric energy consumption (lighting, electric heating, etc.) directly not related to the production process [2-6].

At the same time, not enough attention is paid to the issue of managing energy efficiency in the variable component, which is directly related to the production process.

The present paper proposes a technology for reducing the consumption and losses of electrical energy, which implements the concept of "smart enterprise" and is aimed at improving the energy efficiency of the production processes of railway enterprises.

\section{Concept of technology for reducing consumption and power losses of railway consumers}

\subsection{System for monitoring and managing indicators of energy efficiency}

To implement the proposed technology, it is required to organize a monitoring and management system for indicators of energy efficiency (fig. 2). This system is a system with feedback with automatic control over the deviation. 


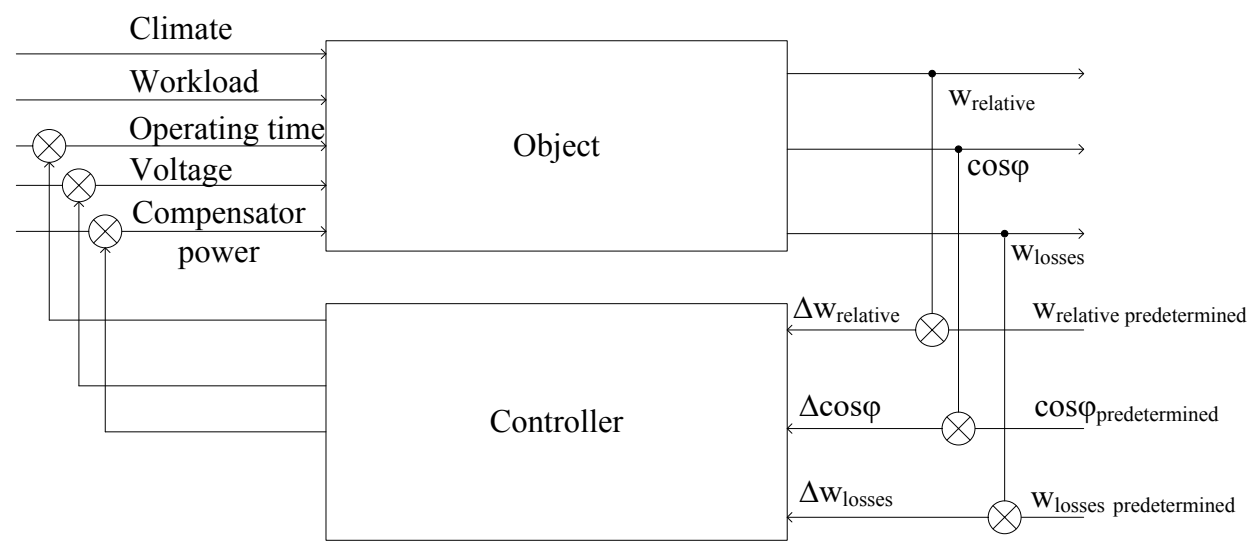

Fig. 2. System for monitoring and managing indicators of energy efficiency.

As the main monitored indicators, specific electric energy consumption $\mathrm{w}_{\text {relative, }}$ power factor $\cos \varphi$, and power loss coefficient $\mathrm{w}_{\text {losses }}$ were adopted.

Factors affecting these indicators can be divided into two groups:

a) independent (climatic indicators, the amount of work) that are conditioned by the production process or external conditions and which are not subject to regulation;

b) dependent (operating time of equipment, voltage of mains, power of the reactive power compensation device), which are controlled by the controller depending on the amount of deviation of the monitored indicators from the set values.

The composition of the monitored indicators and the influencing factors can vary depending on the specific electric energy consumption of the object under study.

Most of the influencing factors applied to the control object can be determined by means of widely used measuring instruments. For example, the voltage level can be monitored using a modern digital electricity meter, a voltmeter or an energy quality analyzer, a temperature - using a temperature sensor, etc. The amount of work can also be monitored using existing work control systems (for example, using the report form "Trips of locomotives" in SLD).

To control the operating time of electrical equipment, the authors developed a device for calculating the operating time [7,8]. The most important element of this device is a measuring unit, which is made in the form of a series-connected alternating magnetic field sensor, amplification and filtering unit, a comparator, and an alternating voltage detector. The sensor of the alternating magnetic field is non-contact and structurally constructed on the basis of an inductive sensor.

\subsection{Defining the set values of the monitored indicators based on the simulation model}

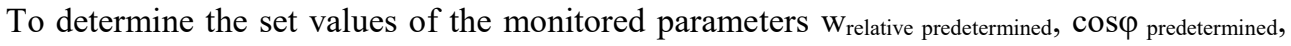

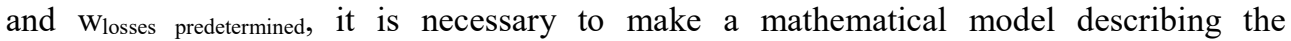
dependence of these values on the factors accepted for consideration. Such a model can be specified both explicitly using a system of differential equations, and implicitly, for example, using an artificial neural network or a simulation model [9-15].

The present study shows an example of the implementation of such a model for a compressor station of SLD Moskovka. The main controlled indicator is power losses $w_{\text {losses }}$ and power factor $\cos \varphi$, and the power of the controlled reactive power compensation device $\mathrm{Q}_{\mathrm{c}}$ as the influencing factor. The simulation model is implemented in the software package MATLAB/Simulink. A general view of it is presented in fig. 3 . 
The compressor station operates 2 compressors: 2BM4-15/25M2 with an asynchronous motor A2K 85/24-8/16 UHL4 with a power of $160 \mathrm{~kW}$ and a VP3-20/9 with an asynchronous electric motor DASK-132 with a power of $132 \mathrm{~kW}$. To cool the compressors, a pump with an electric motor 4A112M2 U3 with a power of $7.5 \mathrm{~kW}$ is used. In winter, the compressor station uses a $2 \mathrm{~kW}$ fan heater.

The asynchronous electric motor of compressors and a pump is most appropriately to be modeled in Simulink as an equivalent circuit (fig. 4). The parameters of this equivalent circuit were calculated by the method [16].

A study of the power curve consumed by the electric motors of the compressors from the network allows us to conclude that for an electric motor of a compressor with a power of $160 \mathrm{~kW}$, the average power consumption is $119 \mathrm{~kW}$, for the second compressor - 111 $\mathrm{kW}$, for the pump motor $-7 \mathrm{~kW}$. Thus, these electric motors constantly operate with a load that is less than the rated load. This load is specified in the model on the motor equivalent circuit in the element $c_{1}^{2} r_{2} / s$ by selecting the value of the current slip $s$ at which the consumed active power $\mathrm{P}_{2}$ will correspond to the average value determined from the load curve.

Compressor power is supplied from the transformer substation with the transformer TM-630/10/0.4, the calculation of its parameters is performed in accordance with the methodology [17].

As a compensating device (CD), a regulated device AUCRM 0.4-120-20-4 with a range of reactive power variation from 0 to $120 \mathrm{kvar}$ in increments of $20 \mathrm{kvar}$ is considered. For its simulating, the Series RLC-Load block can be used. The main parameter of this unit will be the reactive power $\mathrm{Q}_{\mathrm{c}}$ (negative var).

The general view of the model obtained in Simulink is presented on fig. 4.

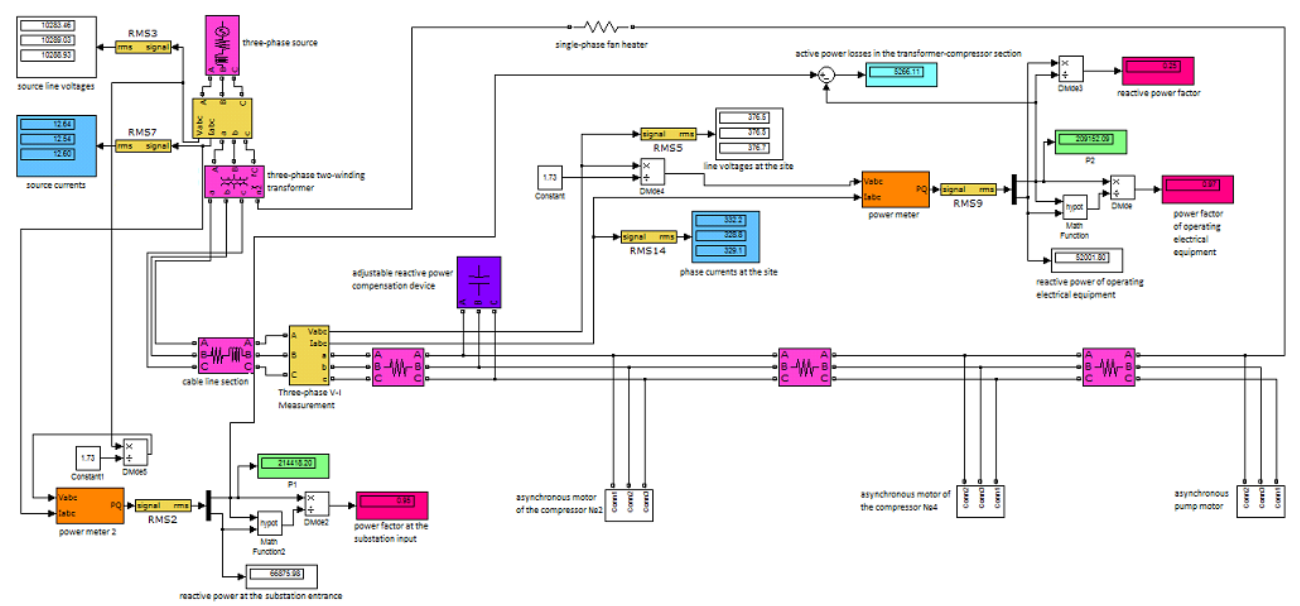

Fig. 3. The model of compressor station of SDl Moskovka in Simulink. 


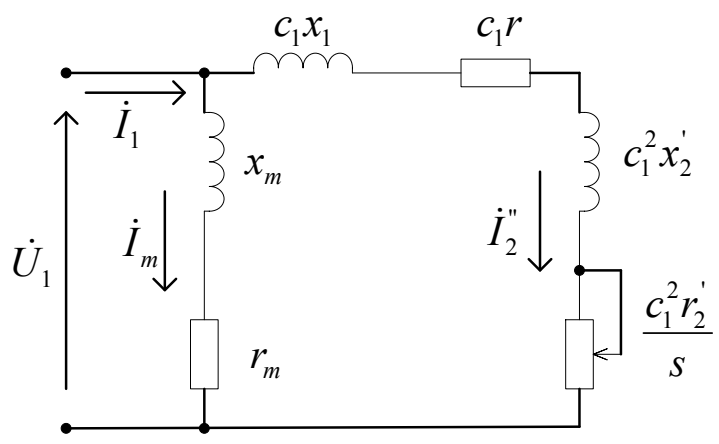

Fig. 4. L-shaped equivalent circuit of one phase of an asynchronous motor.

During the simulation, various combinations of operating devices (load modes) with a successive change in reactive power are considered.

\section{Results}

On the basis of the obtained simulation model, it is possible to estimate the losses of active power for a given mode of operation of electrical equipment for various parameters of the CD.

Fig. 5 shows an example of the dependencies obtained in the course of the simulation for the case when one compressor, pump, and fan heater are in operation.

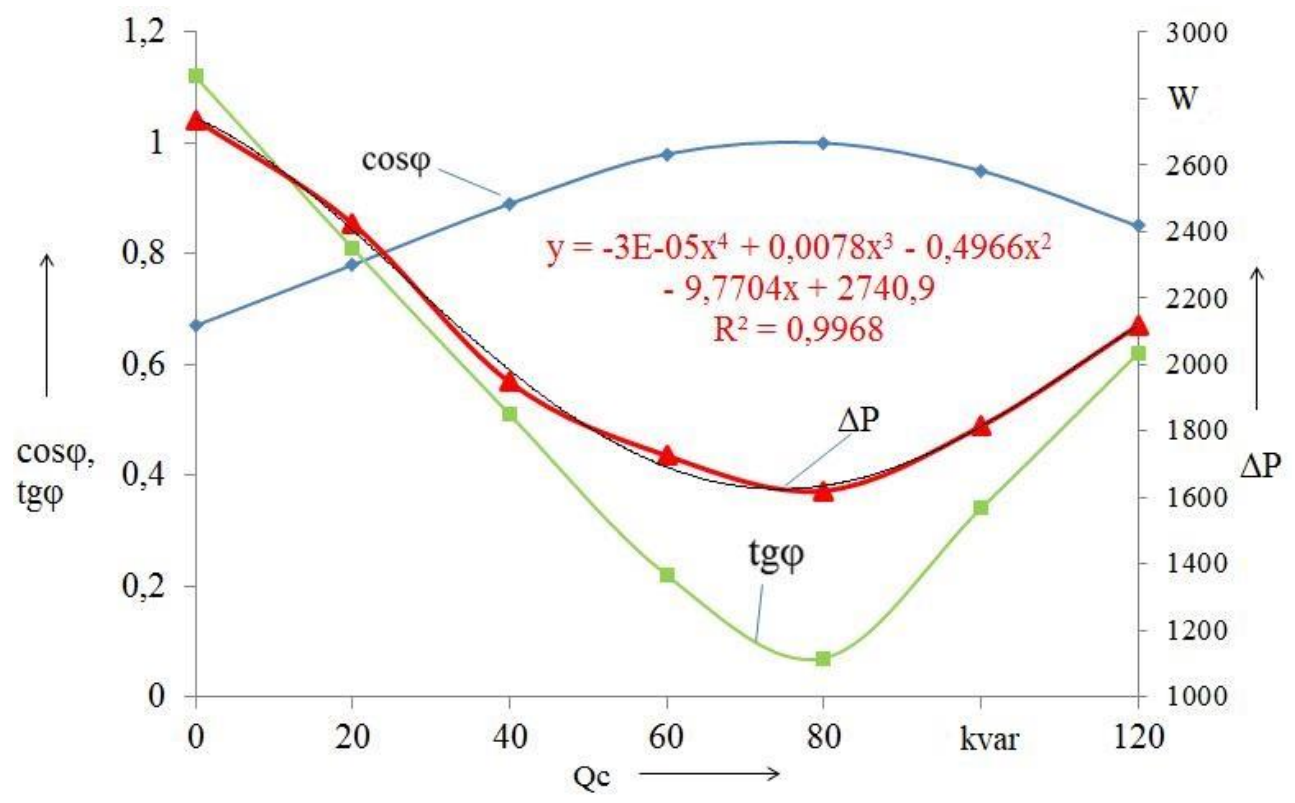

Fig. 5. Dependencies of $\Delta \mathrm{P}, \cos \varphi, \operatorname{tg} \varphi$ on the power of the $\mathrm{CD}$.

In this mode, the smallest losses $\Delta \mathrm{P}$ are observed at $\mathrm{Q}_{\mathrm{c}}=80 \mathrm{kvar}$, they increase with a further increase in the power of the $\mathrm{CD}$; the values of $\cos \varphi$ and $\operatorname{tg} \varphi$ change unevenly in opposite trends with an increase in the power of the CD. 
Thus, in this mode, the set value of power losses and power factor will be achieved at $\mathrm{Q}_{\mathrm{c}}=80$ kvar. Approximating dependences are obtained, which allow determining the $\mathrm{w}_{\text {losses }}$ predetermined for the given mode of operation, which are shown in the graph.

The power losses at the optimal control mode amounted to $1620 \mathrm{~W}$, and in the absence of control, i.e. with the CD switched on to the maximum mode - $2117 \mathrm{~W}$. With the CG switched off, the losses amounted to $2737 \mathrm{~W}$.

Taking into account the fact that during the period under consideration, the scope of work of the enterprise (locomotive repairs) amounted to 26,416 norm. units, the application of the control system will allow reducing the specific power losses from $103.6 \mathrm{~W} /$ norm.un. up to $80.1 \mathrm{~W} /$ norm.un.

\section{Conclusions}

The proposed technology for reducing the consumption and loss of electrical energy for railway consumers includes the following main stages:

a) definition of specific energy efficiency indicators and selection of the least effective structural units;

b) decomposition of structural units to the level of shops, departments, and production sites, and then selection of facilities where the implementation of the management system will be most effective;

c) selection of influencing factors and monitored indicators, equipping the selected facility with the necessary means of measurement, conducting experimental studies;

d) development of a mathematical model and the derivation of dependencies between influencing factors and monitored indicators that will form the basis for management.

According to the results of the simulation modeling of the compressor station of SLD Moskovka in the MATLAB/Simulink program, it has been obtained that as a result of the implementation of the energy efficiency management system, the specific power losses are reduced by $23 \%$. This allows us to talk about the prospect of using this technology on the network of railways and locomotive repair plants.

\section{Acknowledgement}

The authors are grateful to the head of the SLD Moscovka, S.V Chaltsev, for his help in the implementation of the experiment.

\section{References}

1. V. Cheremisin, A. Komyakov, V. Ivanchenko, Journal of Transsib Railway Studies 2(26), 134 - 142 (2016)

2. First smart station in Russia, High-tech buildings 1, 60 - 69 (2013)

3. H. Sengor, C. Kılıçkıran, H. Akdemir, B. Kekezoglu, O. Erdinç, J. P. S. Catalão, 2017 IEEE PES Innovative Smart Grid Technologies Conference Europe (ISGTEurope), 1-6 (2017) doi: 10.1109/ISGTEurope.2017.8260299

4. R. Al-Ali, I. A. Zualkernan, M. Rashid, R. Gupta, M. Alikarar, IEEE Transactions on Consumer Electronics 63-4, 426-434 (2017) doi: 10.1109/TCE.2017.015014

5. O. Ayan, B.E. Turkay, 2017 10th International Conference on Electrical and Electronics Engineering (ELECO), 1247-1252 (2017) 
6. M. Gheydi, P. Farhadi, R. Ghafari, 2016 International Symposium on Fundamentals of Electrical Engineering (ISFEE), $\quad 1-6 \quad$ (2016) doi: 10.1109/ISFEE.2016.7803218

7. V. Ivanchenko, A. Komyakov, Yu. Plotnikov, V. Erbes, Omsk Scientific Bulletin 157, 54-58 (2018)

8. A. Komyakov, V. Erbes, A. Ponomarev, Application of an Intelligent System for the Monitoring of Energy Efficiency Indicators at Service Locomotive Depots, Far East Con-2018 - International multi-conference on industrial engineering and modern technologies

9. W. Zhang, W. Zhao, X. Du, Journal of Networks 9(6), 1502-1508 (2014) doi:10.4304/jnw.9.6.1502-1508

10. D. Wenjin, W. Ping, Natural Computation ICNC 2007, Third International Conference 1, 381-385 (2007) doi: 10.1109/ICNC.2007.260

11. J. Stuchly, S. Misak, T. Vantuch, T. Burianek, IEEE 15th International Conference in Environment and Electrical Engineering (EEEIC) (2015) doi: 10.1109/EEEIC.2015.7165233

12. P. Zhang, H. Wang, Energy Procedia 17, 1332-1338 (2012) doi:10.1016/j.egypro.2012.02.248

13. V. Manusov, K. Boyko, Actual Problems of Electronics Instrument Engineering (APEIE), 2014 12th International Conference, 793-795 (2014) doi: 10.1109/APEIE.2014.7040796

14. A. Badri, Z. Ameli, A. Motie Birjandi, Energy Procedia 14, 1883-1888 (2012) doi:10.1016/j.egypro.2011.12.1183

15. A. Komyakov, M.M. Nikiforov, V.V. Erbes, V.T. Cheremisin, V.I. Ivanchenko, 2016 IEEE 16th International Conference on Environment and Electrical Engineering (EEEIC), 1-4 (2016) doi: 10.1109/EEEIC.2016.7555450

16. M. Makeev, A. Kuvshinov, Vector of science TSU 1(23), 108-112 (2013)

17. A. Novash, Yu. Rumyantsev, Proceedings of the higher educational institutions of the CIS and energy associations 1, 12-24 (2015) 